\title{
Optimization Shortest One-Way Path for Energy Saving Auto Robot Collecting Floating Garbage using Fast Approximate Nearest Neighbor Search
}

\author{
Sumitra Nuanmeesri ${ }^{\mathrm{a},{ }^{*}}$, Lap Poomhiran ${ }^{\mathrm{b}}$ \\ ${ }^{a}$ Faculty of Science and Technology, Suan Sunandha Rajabhat University, Bangkok, 10300, Thailand \\ ${ }^{b}$ Faculty of Information Technology and Digital Innovation, King Mongkut's University of Technology North Bangkok, Bangkok, Thailand \\ Corresponding author: *sumitra.nu@ssru.ac.th
}

\begin{abstract}
Floating garbage is a global problem that needs to be cleared and disposed of from the sea and rivers or canals. Mostly the floating plastic garbage directly affects the ecology and the aquatic animals. This paper proposes to develop a low-cost auto robot from waste materials in the household, school, or agriculture, then combines with the Internet of Things technology and focusing on the power energy saving with the highest accuracy in operation of floating garbage collection. ESP32 development kit board is the primary controller with a camera module and ultrasonic sensor for detecting the floating garbage while moving on the water's surface in the boundary of the specified area, including the small canal, rectangle area, and no rectangle area. The mixed mode is a new method to define the shortest one-way path using a fast approximate nearest neighbor search for the auto robot to detect and collect the floating garbage on the water surface. It was combined between the stationary and the cover model. The mixed mode can eliminate the blind spot area that occurs when using the stationary mode and cover mode. As a result, the auto robot system's accuracy in mixed mode is $\mathbf{9 8 . 3 \%}$. It was found that the development of the shortest one-way path for the auto robot collecting floating garbage by mixed mode provides the highest efficiency in detecting floating garbage and also helps to save overall costs, and the resource consumption is nearly half of cover mode consumption.
\end{abstract}

Keywords-Auto robot; energy saving; floating garbage; image processing; internet of things; low-cost; shortest one-way path.

\section{INTRODUCTION}

Today, most products containing plastic and polymer components. Becoming more waste and an international issue, particularly in different water sources, plastics are not recycled but are left in various ecosystems. For example, in the ocean study, over 150 million tons of waste from plastics found to be deposited onto the sea by consumers totaling eight million tons per year [1]. Some marine animals ingest these plastics because they mistake the plastic debris is shaped like some marine animals or food. Every year, there are many aquatic animals die, such as sea turtles, whales, seals, and seabirds, because of plastic waste pollution [2]. The floating garbage includes plastics, plastic polymers, textiles, foams, glass, and some metal-based wastes, as in Figure 1. This floating garbage continued to create problems both in the short and long term if not urgently addressed. In the shortterm problems, floating garbage affects the amount of dissolved oxygen diffusion through the air and the water surface directly at a depth of less than a millimeter [3]. It will reduce the contact of water surface and obscure the photosynthesis of some plants underwater. The greater the volume of floating waste, it causes to decrease in the efficiency of dissolved oxygen and water quality for aquatic life. Also, floating debris affects water activities, for example, water traffic by boats, fishing, or casting a net in the villagers' culture. It also results in slower drainage, which can lead to flood problems [4].

For long-term problems, floating plastic garbage discharges the organic volatiles and non-volatile compounds it becomes carbon monoxide and carbon dioxide [5]. These plastics generate the dissolved organic carbon (DOC), which is food for bacteria that affect the microbes to stop growing [6]. Especially in places where sunlight is not accessible, these bacteria will grow and eventually lead to wastewater [5]. Plastics are difficult to biodegrade but can break down into smaller pieces such as mesoplastic [7], microplastic, nano 
plastic [6], [8] as plastic debris, which is challenging to detect, monitor, and collect later. This plastic debris can spread from the river to the sea; it affects the coastal ecosystem until the sea and ocean, as mention previously. Moreover, floating garbage also affects the visibility and tourism industry and wastes the budget for managing and solving environmental problems that will follow in the future. Therefore, collaborating to eliminate plastic waste floating in the water is considered to help aquatic animals, aquatic ecosystems and help reduce pollution problems.

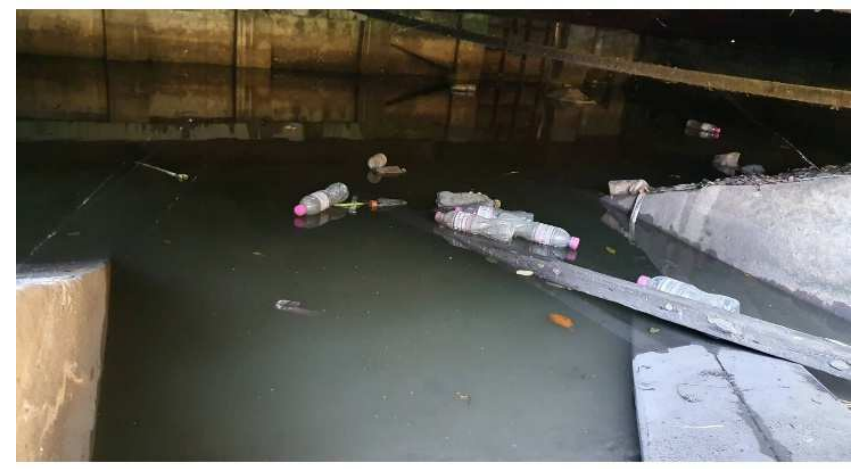

Fig. 1 The plastic waste floating on the water surface

Nowadays, many new technologies can be applied to benefit the ecosystem, especially the Internet of Things (IoT) technology. The technology has been designed and manufactured to be versatile and can be quickly developed at a low-cost. Therefore, the application of modern technology, together with environmental conservation, is a way to help the world to exist under an ecosystem that requires support, monitoring and management with IoT-based [9]-[14]. For example, IoT was conducted to monitoring the water quality such as temperature, $\mathrm{pH}$, and dissolved oxygen in the river [15], [16], lake [17], seawater, domestic stored water in realtime [18], [19] or aquarium system [20], [21]. Besides, IoT can help the user to manage the water by using advanced communication technology such as General Packet Radio Service (GPRS) [22], Global System for Mobile communication (GSM), and Wi-Fi communication in wireless networking technology. Even if integrated with social media such as LINE [23], it will make it more powerful and helps to attract more users and usefulness. LINE has some features to send or alert messages to LINE users by using the application LINE Notify application program interfaces [24], which has libraries that can be run through IoT devices. This feature is a favorite for the application that requires the LINE alert message in real-time monitoring [20]. There are over 44 million LINE users in Thailand, which accounts for 78 percent of mobile internet users [25].

Several forms of the system for handling the floating garbage problem have been developed. Most of them have used stationary such as litter traps [26], [27] or operated remotely [28], which does not allow the robot to operate and move around the water area on its own. According to Abrams [29], the robot can collect waste and track aquatic animals in the water, but it requires humans to control it. Furthermore, the automatic robot system helps clean up plastic wastes at fifty thousand kilograms per day in India and alerts the worker when the bin is full [30]. The Great Pacific Garbage Patch (GPGP) [31] was developed as a vast trawl and used to collect the ocean's debris, but some organisms can be trapped in the trawl is not suitable for small-scale water areas. Some studies found the method to control the robot movement and pathway. For example, the genetic algorithm is used to building up the robot pathfinding [32], and the zigzag path was applied for robot movement to cover all areas [33], [34], which is mostly the way the robots move on the ground [35]-[40]. Some sensors such as ultrasonic, passive infrared, and camera are used to process object detection [41], [42]. An automated robot developed by Nuanmeesri [43] can detect floating garbage, but there are blind spots in the corner of the pool's edge. Therefore, this research aims to develop a low-cost auto robot collecting the floating garbage by focusing on the shortest one-way path to save power consumption and other costs with the highest management efficiency.

\section{MAterials AND MethoD}

In the development of an automated robot for floating plastic garbage collection, with the emphasis on designing robots to set waste collection routes that save energy, but the roll covers the working area. There are many steps for development as follows:

\section{A. Robot Structure Design}

The most crucial thing in robot design in this work is the use of waste materials that are left in the household or from various activities that are materials that are lightweight and can float on water as the main components of the robot structural, which has the following components:

1) Robot Base: Four 5-liters bottles of drinking water used to build the robot base. It has properties like buoyancy to support structures and other components floating above the water surface. Two water bottles on each side are assembled to support the other that will be installed on top.

2) Robot Controller Zone: This component is used to install all IoT controller devices such as microcontroller board, battery pack, camera, and ultrasonic sensor. The central robot controller zone is made from cartons or cardboards for packing household appliances such as television, refrigerators, and washing machines. Containers or cardboard were re-build into a customized and wrapped box with waterproof tape to prevent wet or moisture.

3) Garbage Bin: The garbage bin consists of plastic grates found in gardens or agriculture. It is shaped into a square box with a single front side that is open for garbage floating along the water into a garbage bin. This component is airy, making it easy to see and lightweight, waterproof as well.

4) Paddles: It is made from the future board that is found in the school or advertising board. It is used to drive and move the robot in any direction.

5) Garbage Picker: It is made up of a future board that pushes or grabs the floating garbage on surface water into the trash.

The robot structure is designed as a top view, front view, and side view; it can be illustrated in Figure 2. 


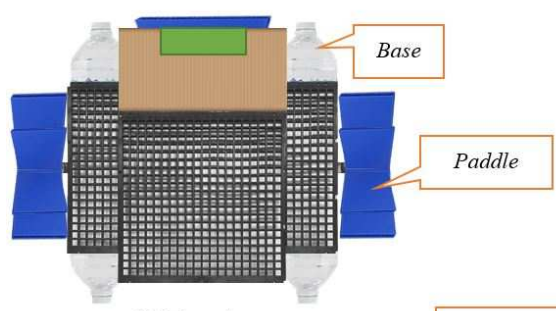

(a) Top view

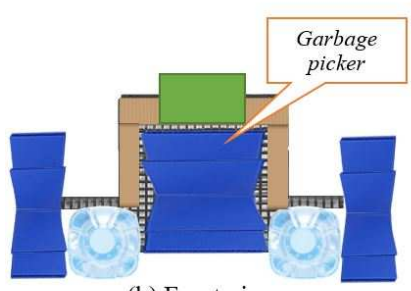

(b) Front view

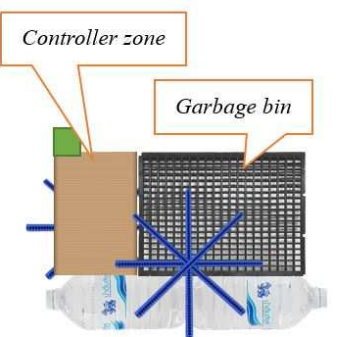

(c) Side view

Fig. 2 The robot structure design for collecting floating garbage

\section{B. Internet of Things Design}

According to Figure 2(c), the robot controller zone consists of electronic devices by using IoT technology. Only the robot paddle, two motors to drive a robot are excluding from the robot controller zone. All IoT devices and sensors were described as follows:

1) ESP32 DevKitC Board: The development kit board is the central control unit for the auto robot. ESP32-series ships are designed for mobile devices and IoT applications with feature ultra-low-power consumption [44]. ESP32-WROOM32 ship was used in this work. It has 38 pins for input and output, both digital and analog signals. The central processor can operate at speed up to 240 megahertz. The Wi-Fi module is included on this board, connecting to the wireless networking up to 150 megabits per second.

2) Two Brushed Direct Current (DC) Geared Motors: Both of these motors are used to support the robot to move in all directions. It serves to rotate the paddle in both clockwise and counterclockwise directions. The brushed DC geared motor is a motor with low speed but high torque that can be easier to bring the robot together with the collected waste.

3) Motor Drive Module (L298N): This module controls both motors' operation above to control the direction of the robot's movement.

4) Single Brushed DC Geared Motor: It is a motor with a slight speed for acting in the garbage picker to grab or push the garbage floating in the front of the robot into the garbage bin.

5) 12Volts-Single Channel Relay: It controls the motor that is a garbage picker to operate when floating waste is detected.

6) Ultrasonic Sensor Module (HC-SR04): It is a sensor that uses sound waves to measure the distance between objects far away with a working range between 0.02 to 4 meters. It serves to detect objects that float on the water surface and the edge of the pool.

7) Camera Module (OV2640): This module is for photographing objects that robots have detected with an ultrasonic sensor for sending images to process objects or sending messages to users as well.

8) Micro Servo (SG90): It is responsible for controlling the vertical angle view of the camera. It can track the objects that are floating until garbage has been collected.

9) Lithium-Ion Batteries and Battery Pack: It is the power source for the processor within the controller zone and all activities used in the robot's operations. This battery pack consists of 24 cells of rechargeable battery in series 18650 with a current of 3.4 Amperes (A) and a voltage of 3.7 Volts (V) capacities for each cell. The final electric current of 27.2A and $11.1 \mathrm{~V}$ can support $12 \mathrm{~V}$ of Internet of Things devices by connecting each cell in series and parallel.

The power consumption of IoT devices used to construct the robot was shown in Table I, and the IoT design can illustrate in Figure 3.

TABLE I

THE POWER CONSUMPTION OF IOT DEVICES AND SENSORS For THE Auto Robot COLLECTING FLOATING GARBAGE

\begin{tabular}{lll}
\hline IoT devices and sensors & $\begin{array}{l}\text { Voltage } \\
\text { (V) }\end{array}$ & $\begin{array}{l}\text { Power } \\
\text { consumption } \\
\text { (mA) }\end{array}$ \\
\hline $\begin{array}{l}\text { ESP32 DevKitC (no WiFi } \\
\text { operation) at 240 MHz }\end{array}$ & 3.6 & 50 \\
ESP32 DevKitC (WiFi operation) & 3.6 & 130 to 230 \\
at 240 MHz & 12 & 0.5833 \\
Two brushed DC geared motors & 12 & 36 \\
$\begin{array}{l}\text { Motor drive module (L298N) } \\
\text { Single brushed DC geared motor }\end{array}$ & 12 & 0.0325 \\
12V-Single channel relay & 12 & 0.0375 \\
$\begin{array}{l}\text { Ultrasonic sensor module (HC- } \\
\text { SR04) }\end{array}$ & 5 & 15 \\
Camera module (OV2640) & 3.3 & 0.0424 \\
\hline
\end{tabular}

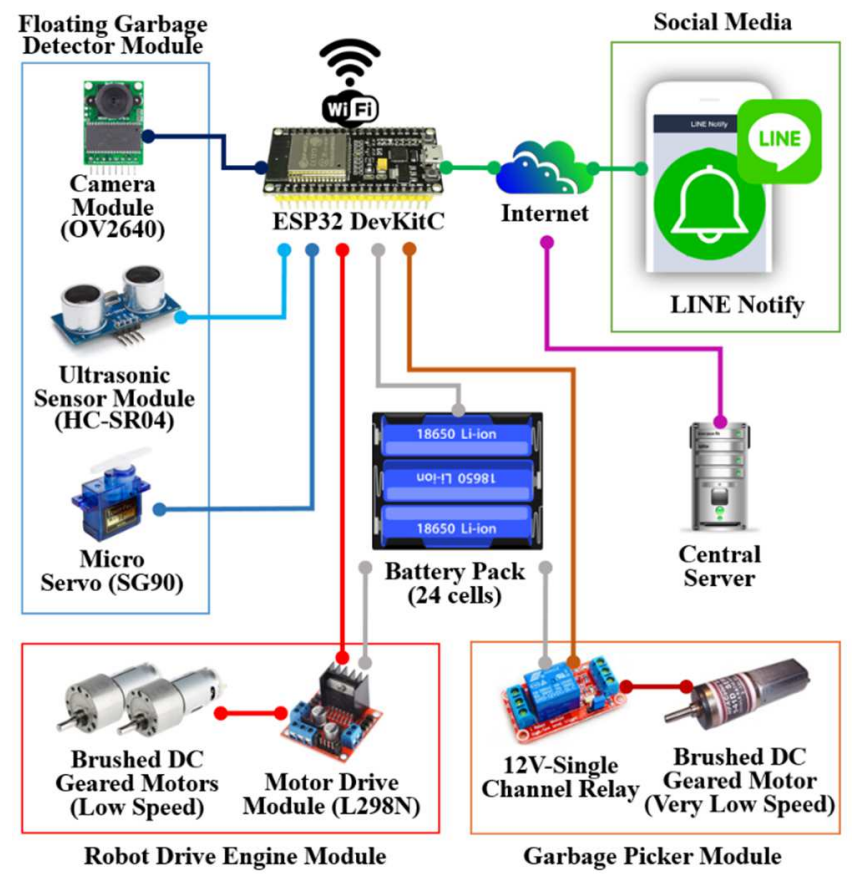

Fig. 3 The IoT and sensors devices used to construct the robot 


\section{Shortest One-Way Path of Energy Saving}

According to Nuanmeesri [43], there are two modes of robot operation: stationary and cover modes. Both modes can be illustrated in Figure 4.

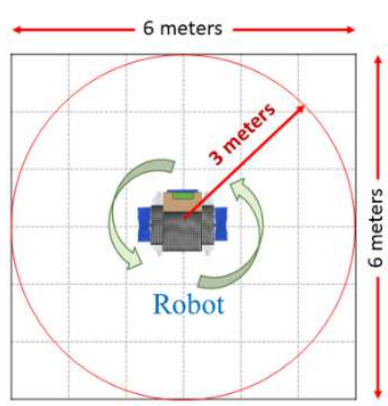

(a) Stationary mode

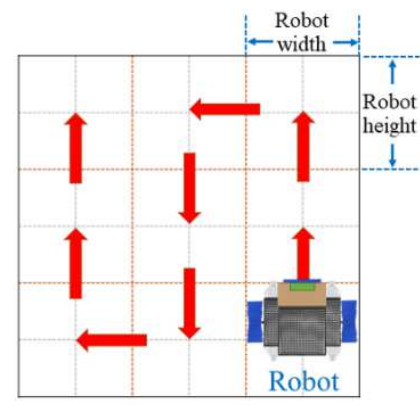

(b) Cover mode
Fig. 4 The robot operation in stationary mode and cover mode

This research designed a robot walking path by combining both modes. This method was called the mixed mode. The ultrasonic sensor can operate to detect an object in the distance range of 2 to 400 centimeters. In this work, the researchers control the effectual distance range that does not exceed 300 centimeters that ultrasonic sensors can detect an object.

Considering Figure 4(a), the stationary mode can cover the area in 36 square meters, which is the robot standing by and waiting for the floating garbage move followed by the water flow. This work, the robot dimension, is $100 \times 100$ centimeters. The researchers adjusted the area for the robot to detect floating debris by specifying the area with a half-size robot combined with the distance that ultrasonic can detect. Resulting in a new coverage area equal to 49 square meters calculated in (1) and (2).

$$
\begin{gathered}
D_{\text {new }}=\left(\frac{W_{\text {robot }}}{2}+D_{\text {seessor }}\right)^{2} \\
A_{\text {new }}=D_{\text {new }}^{2}
\end{gathered}
$$

Where:

$D_{\text {new }}$ refers to the new distance the reach to detect an object floating on the water surface.

$A_{\text {new }}$ refers to the new coverage area of the robot.

$W_{\text {robot }}$ refers to the width of the robot dimension (100 centimeters).

$D_{\text {sensor }}$ refers to ultrasonic sensor distance detection (300 centimeters).

For the mixed mode, the shortest one-way path is applied to cover all new coverage areas. The robot works by moves forward to each new coverage area, then rotates left by itself a total of 12 times to cover the area in 360 degrees within 49 square meters. Each rotation covers an area in 30 degrees. However, a few areas do not detect a sensor; it was called the blind spot area. These blind spot areas are shown in Figure 5. The blind spot areas are eliminated by the robot move forward in a half-distance of coverage area then rotates twice times on the right-hand side of the robot to detect the floating garbage at the blind spot area right-hand side. After that, turn the robot around 180 degrees to detect an object on the left-hand side by rotating twice. When finished, it will move forward to enter the new coverage area that is next. The robot operation for blind spot area elimination is shown in Figure 6.

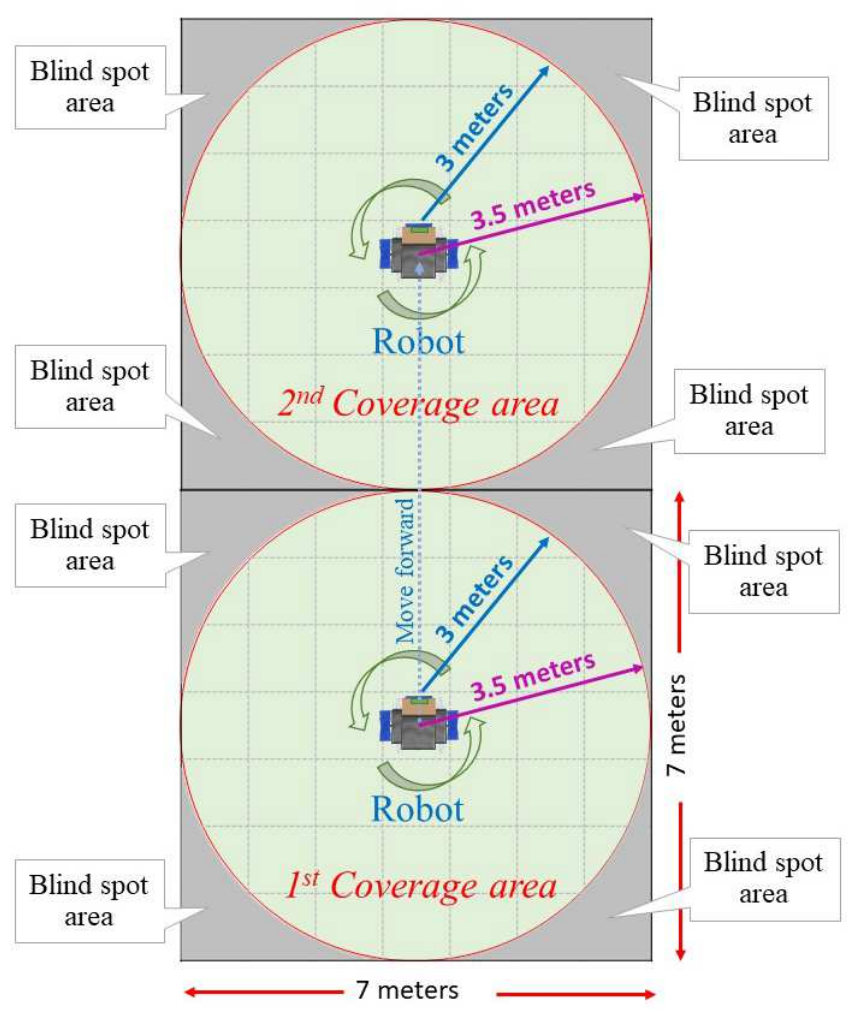

Fig. 5 The blind spot areas when the robot rotates 360 degrees

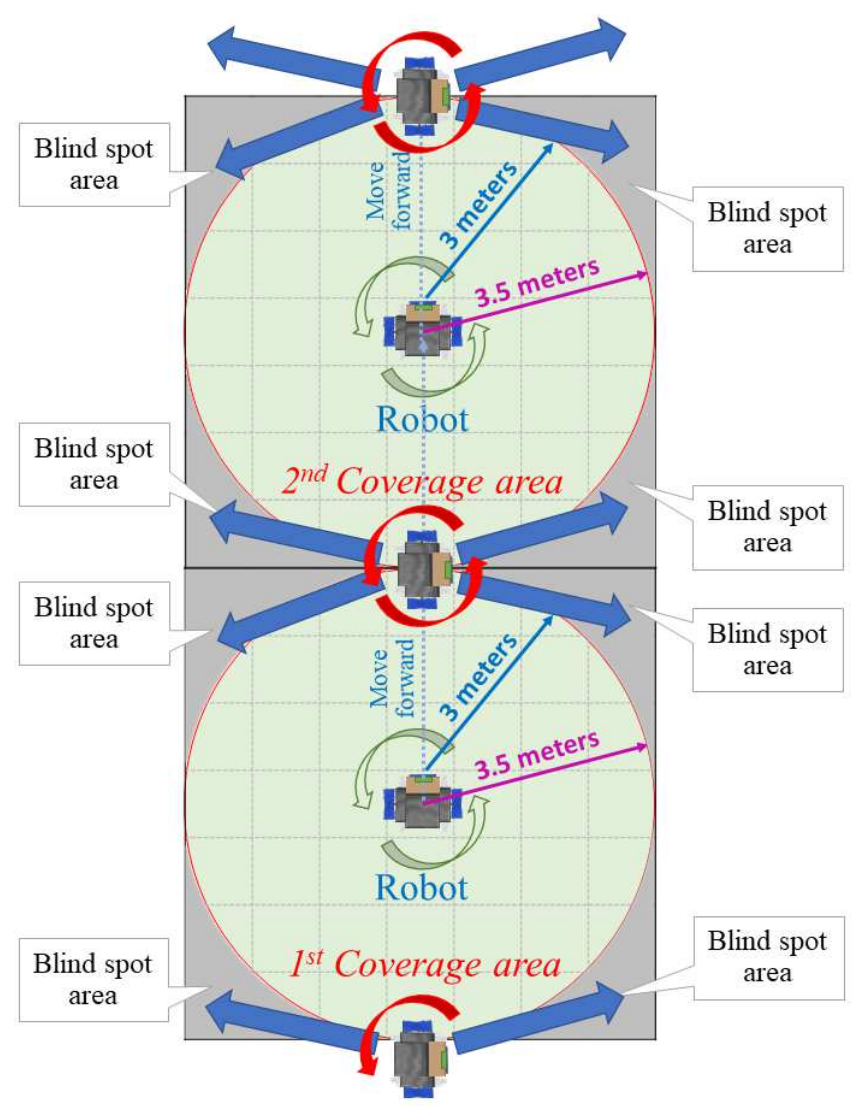

Fig. 6 The blind spot areas eliminated strategy in mixed mode.

When comparing the cover mode and the mixed mode in this work design, it can calculate the energy or power 
consumption and the total distance for moving the robot to cover all target areas. For cover mode, the total distance can calculate in (3).

$$
D_{\text {total }}=\frac{A_{\text {total }}}{D_{\text {robot }}}
$$

Where:

$D_{\text {total }}$ refers to the total distance that robot movement all cover areas.

$A_{\text {total }}$ refers to the entire area in the pool reserved for robot operation.

$D_{\text {robot }}$ refers to a robot's dimension, the robot width multiply by robot height (from top view).

For the robot operation in mixed mode, according to a new distance $D_{\text {new }}$ in (1), which is the width of the robot plus the distance of the ultrasonic sensor can be reached. Thus, $D_{\text {new }}$ instead of $D_{\text {robot }}$, the total distance $D_{\text {total }}$ can calculate in (4).

$$
D_{\text {total }}=\frac{A_{\text {total }}}{D_{\text {new }}}
$$

For example, the pool's total area is 1,000 square meters, and the dimension of the robot is $1 \times 1$ meters. The total distance calculates in (3) for cover mode; it is 1,000 square meters divided by a square meter, the 1,000 times of robot movement in cover mode. In contrast, the total distance in a mixed mode calculates in (1) and (4). It is 1,000 square meters divided by 49 square meters. The result is 20.41 , meaning that the robot moves 21 times to cover all areas in a pool. This mixed mode reduces $97.9 \%$ of the distance to move the robot.

\section{System Development}

Arduino IDE version 1.8.13 is used to develop the system for control the robot for movement, garbage detection, grabbing, and internet communication. This system was developed and loaded into the ESP32 DevKitC board. During floating garbage detection, the ultrasonic sensor will be detecting an object on the water surface. If an object is found, it will activate the camera for a snapshot image then send it to the central server. The web application programming interface (API) was developed and installed at the central server based on Python version 3.6.5. Three thousand images were used in the training process for floating garbage classification. This server will process the image to classify the object, which is garbage or not, by using the fast Approximate Nearest Neighbor search algorithm [45], [46], [47], [48], [49], [50] with low power consumption [51]. Fast Approximate Nearest Neighbor search can determine the suitable configuration for hierarchical $k$-means trees and the randomized K-Dimensional trees [52], [53], [54] under the kNN protocol [55]. The overall cost can be computed in (5) [45].

$$
\operatorname{cost}=\frac{t_{s}+t_{w} b}{\left(t_{s}+t_{w} b\right)_{o p t}}+m_{w} r
$$

Where:

$t_{s}$ refers to the searching time in the image dataset.

$t_{w}$ refers to the building time weight.

$b$ refers to the tree building time.

$m_{w}$ refers to the memory weight.

$r$ refers to the ratio of the memory used for the tree to store the data.

$\left(t_{s}+t_{w} b\right)_{\text {opt }}$ refers to the optimum time cost.
The FLANN library in OpenCV was used to train these images and classify the plastic floating garbage on the water surface by applying the region of interest of the garbage images.

An example of source code for the robot working system is shown in Figure 7, and the web API for classifying the floating garbage on the central server is shown in Figure 8.

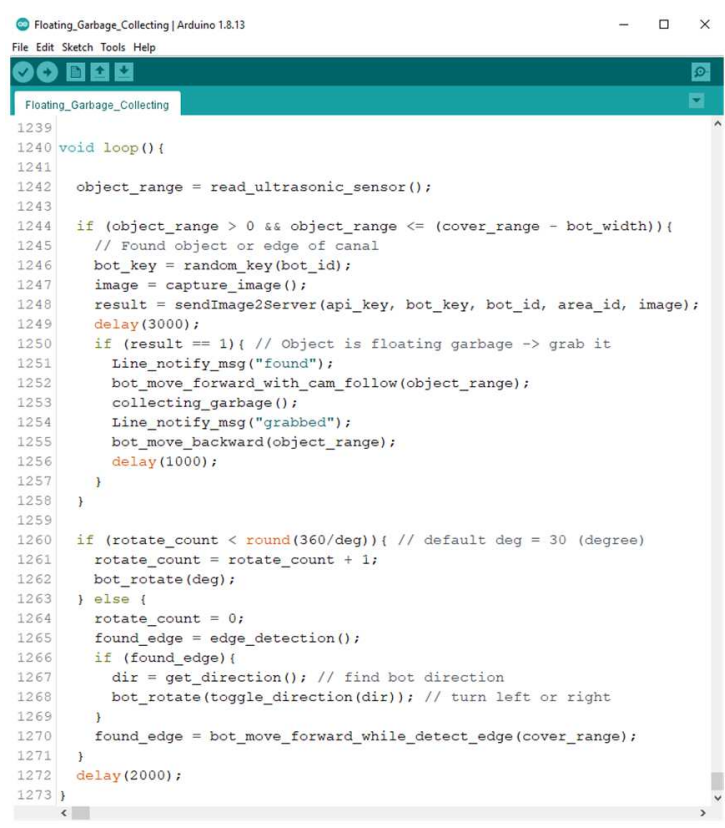

Fig. 7 An example of coding of main loop function on the robot

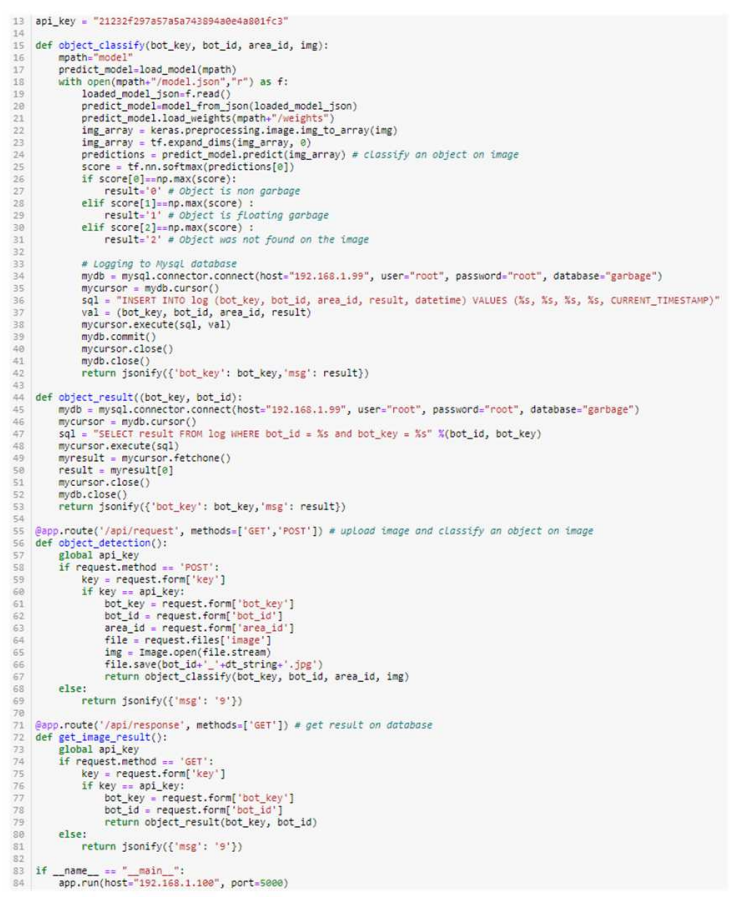

Fig. 8 An example of coding of the web API on the central server

If an object is a plastic floating garbage, such as a bottle, the garbage picker will activate to grab and push the garbage into the bin. Finally, The ESP32 will send the message to LINE Notify, a free mobile application on social media for the system manager or garbageman, shown in Figure 9. 


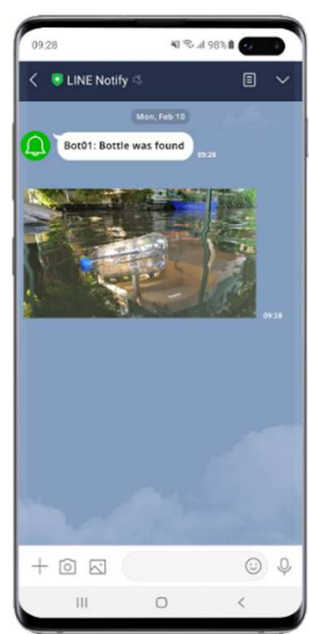

Fig. 9 The alert message from the robot to LINE Notify application

\section{E. System Evaluation}

This auto robot collecting floating garbage system was evaluated in terms of system efficiency and energy saving by comparing it in three modes: stationary mode, cover mode, and mixed mode. All evaluations were tested in three kinds of pool and canal, which is a low speed of water flow. The first kind is the small canal that is not too wide $(6.5 \times 50$ meters for width and length, respectively). The second kind is a pool that is formed in a rectangle area with $16 \times 30$ meters dimensional. The last kind is the non-rectangle area in 560 square meters. The floating objects were set randomly, both garbage and no garbage, which are the same amount of floating objects. This system is tested in a closed system. At the end of the evaluation, we check the remaining power source of a battery pack installed on the robot.

\section{RESULTS AND DISCUSSION}

In this experiment, the robot was installed, tested, and evaluated in a closed system with a maximum robot operation time limit of 180 minutes. The researchers define A1, A2, and A3 are the small canal, rectangle area, and no rectangle area, respectively. Moreover, the robot operation modes are defined as S, C, and M for stationary mode, cover mode, and mixed mode, respectively. The results of the system evaluation shown in Table II.

\section{TABLE II}

THE RESUlt OF THE SYSTEM EVALUATION OF RoBot COLLECTING FLOATING GARBAGE IN THREE MODE

\begin{tabular}{|c|c|c|c|c|c|c|c|c|c|}
\hline \multirow{3}{*}{$\begin{array}{l}\text { Term of } \\
\text { evaluation }\end{array}$} & \multicolumn{9}{|c|}{ Results of the system evaluation } \\
\hline & \multicolumn{3}{|c|}{ A1 (6.5x50) } & \multicolumn{3}{|c|}{ A2 (16x30) } & \multicolumn{3}{|c|}{ A3 } \\
\hline & $\mathbf{S}$ & $\mathbf{C}$ & $\mathbf{M}$ & $\mathbf{S}$ & $\mathbf{C}$ & $\mathbf{M}$ & $\mathbf{S}$ & $\mathbf{C}$ & $\mathbf{M}$ \\
\hline $\begin{array}{l}\text { Total area } \\
\text { (square meters) }\end{array}$ & 325 & 325 & 325 & 480 & 480 & 480 & 560 & 560 & 560 \\
\hline $\begin{array}{l}\text { Operation time } \\
\text { (minutes) }\end{array}$ & 89 & 77 & 44 & 180 & 95 & 53 & 180 & 117 & 68 \\
\hline $\begin{array}{l}\text { Power } \\
\text { consumption (\% } \\
\text { of current } \\
\text { maximum at } \\
27.2 \mathrm{~A}, 11.1 \mathrm{~V})\end{array}$ & 35.2 & 51.4 & 22.9 & 43.1 & 69.5 & 38.0 & 40.4 & 85.9 & 45.7 \\
\hline $\begin{array}{l}\text { Robot walking } \\
\text { distance in real- } \\
\text { world (meters) }\end{array}$ & 165 & 352 & 137 & 53 & 495 & 269 & 26 & 614 & 314 \\
\hline $\begin{array}{l}\text { Floating garbage } \\
\text { remaining }(\%)\end{array}$ & 12 & 4 & 0 & 92 & 6 & 1 & 96 & 8 & 2 \\
\hline
\end{tabular}

According to Table II, the mixed mode consumes all resources less than other modes. For mixed mode, it takes 44, 53, and 68 minutes for the small canal, rectangle area, and no rectangle area in the term of the operation time, respectively. The power consumption consumes $22.9 \%, 38.0 \%$, and $45.7 \%$ of a battery pack for the small canal, rectangle area, and no rectangle area, respectively. The robot walking distance in the real-world moves on the water surface at 137, 269, and 314 meters for the small canal, rectangle area, and no rectangle area, respectively. Last, the floating garbage remaining, mixed mode remains a few floating garbage in the testing area. When comparing the cover mode and mixed-mode, mixed mode resource consumption is nearly half of cover mode consumption. For the system efficiency evaluation, the results show in Table III.

TABLE III

THE EFFICIENCY OF RoBot COLLECTING FLOATING GARBAGE IN THREE MODE

\begin{tabular}{llll}
\hline \multirow{2}{*}{ Indicators } & \multicolumn{3}{c}{ Accuracy (\%) } \\
\cline { 2 - 4 } & $\mathbf{S}$ & $\mathbf{C}$ & $\mathbf{M}$ \\
\hline Floating object detection & 89.5 & 98.2 & 99.1 \\
Floating garbage classification & 92.5 & 92.5 & 92.5 \\
Floating garbage collecting & 100.0 & 100.0 & 100.0 \\
Movement cover area defined & 90.0 & 99.2 & 100.0 \\
Messaging to social media & 100.0 & 100.0 & 100.0 \\
Average mean & $\mathbf{9 4 . 4}$ & $\mathbf{9 8 . 0}$ & $\mathbf{9 8 . 3}$ \\
\hline
\end{tabular}

According to Table III, the mixed mode has an accuracy higher than stationary and cover mode in terms of floating object detection and movement cover area defined. For the movement cover area defined, the robot can cover all areas by $100 \%$. Overall, the average mean, mixed mode accuracy at $98.3 \%$, is higher than other modes. The stationary mode results will reduce the floating object detection efficiency when the area is more comprehensive or increased. This mode will not move continuously like other modes, which will move in the radius that is at the beginning, which is suitable for the case of water flowing through the robot that is responsible for monitoring or detecting objects that float into the specified radius only.

\section{CONCLUSION}

The low-cost auto robot collecting the floating garbage, it constructed by waste materials found in household, school, or agriculture. When it combines with the IoT technology, it is useful to help the ecology. This work, the auto robot system, was developed in Arduino and Python for improving the plastic floating garbage detection and collection using Fast Approximate Nearest Neighbor search. The mixed mode is a new method for the shortest one-way path to save the cost of time and power consumption. In the same way, when tested and compared with other modes, it was found that this mode was more efficient in collecting floating garbage than other modes. As a result, the accuracy of the auto robot system in mixed mode is $98.3 \%$. It can be said that the development of the shortest one-way path for the auto robot collecting floating garbage by mixed mode provides the highest efficiency in detecting floating debris and also helps to save overall costs.

For further research, the researchers will develop the application in the segmented workspace controls or limit the collaboration area's scope with other robots to cover wide areas and prevent overlapping work areas. It will also develop 
automatic work schedules, including notification if the trash is full and calculating the amount of remaining battery power for the robot to return to its starting point, or to a resting point for charging, or as a littering point. Besides, there must be compensation for the robot's movement on the water flow using the global positioning system (GPS) to recognize where the robot will be moving.

\section{ACKNOWLEDGMENT}

We are grateful to the Institute for Research and Development, Suan Sunandha Rajabhat University, and Faculty of Information Technology and Digital Innovation, King Mongkut's University of Technology North Bangkok, who supported and gave an opportunity in this research.

\section{REFERENCES}

[1] World economic forum. (2019). We must stop choking the ocean with plastic waste. Here's how. [Online]. Available: https://www.weforum.org/agenda/2019/01/we-can-stop-choking-ouroceans-with-plastic-waste-heres-how/

[2] Surfers against sewage. (2019). Plastic pollution- facts and figures. [Online]. Available: https://www.sas.org.uk/our-work/plasticpollution/plastic-pollution-facts-figures/

[3] J. Rahlff et al., "Oxygen profiles across the sea-surface microlayereffects of diffusion and biological activity," Frontiers in Marine Science, vol. 6, pp. 11, 2019, doi: 10.3389/fmars.2019.00011.

[4] F. M. Windsor et al., "A catchment-scale perspective of plastic pollution," Global Change Biology, vol. 25, no. 4, pp. 1207-1221, 2019, DOI: $10.1111 / \mathrm{gcb} .14572$.

[5] C. Romera-Castillo, M. Pinto, T. M. Langer, X. A. Álvarez-Salgado, and G. J. Herndl, "Dissolved organic carbon leaching from plastics stimulates microbial activity in the ocean," Nature Communications, vol. 9, pp. 1430, 2018, doi: 10.1038/s41467-018-03798-5.

[6] L. Zhu, S. Zhao, T. B. Bittar, A. Stubbins, and D. Li, "Photochemical dissolution of buoyant microplastics to dissolved organic carbon: Rates and microbial impacts," Journal of Hazardous Materials, vol. 383, pp. 121065, 2020, doi: 10.1016/j.jhazmat.2019.121065.

[7] T. van Emmerik and A. Schwarz, "Plastic debris in rivers," WIREs Water, vol. 7, no. 1, 2019, doi: 10.1002/wat2.1398.

[8] D. Ó. Conchubhair et al., "Joint effort among research infrastructures to quantify the impact of plastic debris in the ocean," Environmental Research Letters, vol. 14, no. 6, pp. 065001, 2019, doi: 10.1088/17489326/ab17ed.

[9] X. Li et al., "Internet of Things to network smart devices for ecosystem monitoring," Sci. Bull., vol. 64, no. 17, pp. 1234-1245, 2019, doi: 10.1016/j.scib.2019.07.004.

[10] S. Liu et al., "The Heihe integrated observatory network: A Basinscale land surface processes observatory in China," Vadose Zo. J., vol. 17, no. 1, p. 180072, Jan. 2018, doi: 10.2136/vzj2018.04.0072.

[11] J. Kang, R. Jin, X. Li, C. Ma, J. Qin, and Y. Zhang, "High spatiotemporal resolution mapping of soil moisture by integrating wireless sensor network observations and MODIS apparent thermal inertia in the Babao River basin, China," Remote Sens. Environ., vol. 191, pp. 232-245, 2017, doi: 10.1016/j.rse.2017.01.027.

[12] D. Pasetto et al., "Integration of satellite remote sensing data in ecosystem modelling at local scales: Practices and trends," Methods Ecol. Evol., vol. 9, no. 8, pp. 1810-1821, Aug. 2018, doi: 10.1111/2041-210X.13018.

[13] X. Luo and J. Yang, "Water pollution detection based on hypothesis testing in sensor networks," J. Sensors, vol. 2017, p. 3829894, 2017, doi: $10.1155 / 2017 / 3829894$

[14] H. Zemrane, Y. Baddi, and A. Hasbi, "Internet of things Ad Hoc drones' ecosystem," Procedia Comput. Sci., vol. 175, pp. 716-722, 2020, doi: $10.1016 /$ j.procs.2020.07.106.

[15] M. S. U. Chowdury et al., "IoT based real-time river water quality monitoring system," Procedia Comput. Sci., vol. 155, pp. 161-168, 2019, doi: $10.1016 /$ j.procs.2019.08.025.

[16] H. Jindal, S. Saxena, and S. S. Kasana, "A sustainable multiparametric sensors network topology for river water quality monitoring," Wirel. Networks, vol. 24, no. 8, pp. 3241-3265, 2018, doi: 10.1007/s11276-017-1532-z.
[17] H. Cao, Z. Guo, S. Wang, H. Cheng, and C. Zhan, "Intelligent widearea water quality monitoring and analysis system exploiting unmanned surface vehicles and ensemble learning," Water, vol. 12, no. 3, pp. 681, 2020, doi: 10.3390/w12030681.

[18] L. Kuski, E. Maia, P. Moura, N. Caetano, and C. Felgueiras, "Development of a decentralized monitoring system of domestic water consumption," Energy Reports, vol. 6, pp. 856-861, 2020, doi: 10.1016/j.egyr.2019.11.019.

[19] K. Saravanan, E. Anusuya, R. Kumar, and L. H. Son, "Real-time water quality monitoring using Internet of Things in SCADA," Environ. Monit. Assess., vol. 190, no. 9, p. 556, 2018, doi: 10.1007/s10661-0186914-x.

[20] S. Nuanmeesri and L. Poomhiran, "Improvement of smart farm by using IoT for ornamental fishes and aquatic animals store," International Journal of Innovative Technology and Exploring Engineering, vol. 9, no. 3, pp. 2201-2206, 2020, doi: 10.35940/ijitee.C8962.019320.

[21] W. Chen et al., "Farm ponds in southern China: Challenges and solutions for conserving a neglected wetland ecosystem," Sci. Total Environ., vol. 659 , pp. 1322-1334, 2019, doi 10.1016/j.scitotenv.2018.12.394.

[22] X. Wang, L. Ma, and H. Yang, "Online water monitoring system based on ZigBee and GPRS," Procedia Eng., vol. 15, pp. 2680-2684, 2011, doi: 10.1016/j.proeng.2011.08.504.

[23] LINE Corporation. (2020). LINE. [Online]. Available: https://line.me/en/

[24] LINE Corporation. (2020). LINE Notify API Document. [Online]. Avaliable: https://notify-bot.line.me/doc/en/

[25] TaTaTaTan. (2019, July 25). Life on LINE 2019. [Online]. Available: https://www.whatphone.net/news/pr/line-converge-thailand-2019life-on-line/

[26] P. Vriend et al., "Rapid assessment of floating macroplastic transport in the Rhine," Frontiers in Marine Science, vol. 7, pp. 10, 2020, doi: 10.3389/fmars.2020.00010.

[27] N. K. A. Malik et al. "Variation of floatable litter load and its compositions captured at floating debris boom (FDB) structure," Journal of Material Cycles and Waste Management, vol. 22, no. 6, pp. 1744-1767, 2020, doi: 10.1007/s10163-020-01065-8.

[28] A. Xing, J. Fang, M. Gao, and C. Zhang, "Design of an unmanned boat system for floating garbage salvage and water quality monitoring based on OneNET," Journal of Physics: Conference Series, vol. 1607 pp. 012062, 2020, doi: 10.1088/1742-6596/1607/1/012062.

[29] M. Abrams. (2018). Remote robot cleans trash from water. [Online]. Available: https://www.asme.org/topics-resources/content/remoterobot-cleans-trash-water/

[30] India Block. (2019). The ocean cleanup launches system to catch plastic waste in rivers. [Online]. Available: https://www.dezeen.com/2019/10/29/ocean-cleanup-interceptorriver-plastic-pollution/

[31] L. Lebreton et al., "Evidence that the Great Pacific Garbage Patch is rapidly accumulating plastic," Nature Research, vol. 8, pp. 4666, 2018, doi: 10.1038/s41598-018-22939-w.

[32] J. Ma, Y. Liu, S. Zang, and L. Wang, "Robot path planning based on Genetic Algorithm fused with Continuous Bezier Optimization," Comput. Intell. Neurosci., vol. 2020, p. 9813040, 2020, doi: $10.1155 / 2020 / 9813040$

[33] B. Li, H. Liu, and W. Su, "Topology optimization techniques for mobile robot path planning," Appl. Soft Comput., vol. 78, pp. 528-544, 2019, doi: $10.1016 /$ j.asoc.2019.02.044.

[34] J. Lee, A. S. Ab Ghafar, N. Mohd Nordin, F. A. Saparudin, N. Katiran, "Autonomous multi-function floor cleaning robot with zig zag algorithm," Indonesian Journal of Electrical Engineering and Computer Science, vol. 15, no. 3, pp. 1653, 2019, doi: 10.11591/ijeecs. v15.i3.pp1653-1661.

[35] T. B. Asafa, T. M. Afonja, E. A. Olaniyan, and H. O. Alade, "Development of a vacuum cleaner robot," Alexandria Eng. J., vol. 57, no. 4, pp. 2911-2920, 2018, doi: 10.1016/j.aej.2018.07.005.

[36] S. Yatmono, M. Khairudin, H. S. Pramono, and A. Asmara, "Development of intelligent floor cleaning robot," J. Phys. Conf. Ser., vol. 1413, p. 12014, 2019, doi: 10.1088/1742-6596/1413/1/012014.

[37] P. S. Adithya, R. Tejas, V. Sai Varun, and B. N. Prashanth, "Design and development of automatic cleaning and mopping robot," IOP Conf. Ser. Mater. Sci. Eng., vol. 577, p. 12126, 2019, doi: 10.1088/1757$899 \mathrm{x} / 577 / 1 / 012126$

[38] B. R. Chang, H.-F. Tsai, J.-L. Lyu, and T.-K. Yin, "Smart trash can robot system with integration of internet of things and mobile 
applications," Sensors and Materials, vol. 31, no. 11, pp. 3495-3516, 2019, doi: 10.18494/SAM.2019.2563.

[39] J. Bai, S. Lian, Z. Liu, K. Wang, and D. Liu, "Deep learning based robot for automatically picking up garbage on the grass," IEEE Trans. Consum. Electron., vol. 64, no. 3, pp. 382-389, 2018, doi: 10.1109/TCE.2018.2859629.

[40] B. Murdyantoro, D. S. Eka Atmaja, and H. Rachmat, "Application design of farmbot based on Internet of Things (IoT)," Int. J. Adv. Sci. Eng. Inf. Technol. Vol. 9 No. 4, pp. 1163-1170, 2019, doi: 10.18517/ijaseit.9.4.9483.

[41] A. Anitha, "Garbage monitoring system using IoT," IOP Conf. Ser. Mater. Sci. Eng., vol. 263, p. 42027, 2017, doi: 10.1088/1757$899 x / 263 / 4 / 042027$

[42] D. V. B. Pragna, D. L. Reddy, and SVS Prasad, "IoT driven automated object detection algorithm for urban surveillance system in smart city," International Journal of Engineering and Advanced Technology, vol. 8, no. 6S3, pp. 1687-1691, 2019, doi: 10.35940/ijeat.F1317.0986S319.

[43] S. Nuanmeesri, "Development of low-cost auto robot for plastic floating garbage collection using IoT," International Journal of Engineering and Advanced Technology, vol. 9, no. 2, pp. 3727-3732, 2019, doi:10.35940/ijeat.B4557.129219.

[44] Espressif Systems. (2019). Espressif Documentation. [Online]. Available:

https://www.espressif.com/en/support/documents/technicaldocuments/

[45] M. Muja and D. G. Lowe, "Fast approximate nearest neighbors with automatic algorithm configuration," Proc. of the Fourth International Conference on Computer Vision Theory and Applications, 2009, vol. 1, pp. 331-340.

[46] K. Hajebi, Y. Abbasi-Yadkori, H. Shahbazi, and H. Zhang, "Fast approximate nearest-neighbor search with k-nearest neighbor graph," Proc. of the Twenty-Second International Joint Conference on Artificial Intelligence, 2000, pp. 1312-1317.

[47] D. A. Suju and H. Jose, "FLANN: Fast approximate nearest neighbour search algorithm for elucidating human-wildlife conflicts in forest areas," Proc. of 2017 Fourth International Conference on Signal Processing, Communication and Networking, 2017, pp. 1-6.

[48] S. An et al., "Quarter-point product quantization for approximate nearest neighbor search," Pattern Recognit. Lett., vol. 125, pp. 187194, 2019, doi: 10.1016/j.patrec.2019.04.017.

[49] C. Fu, C. Xiang, C. Wang, and D. Cai, "Fast Approximate Nearest Neighbor search with the navigating spreading-out graph," Proc. VLDB Endow. vol. 12, no. 5, pp. 461-474, 2019, doi: $10.14778 / 3303753.3303754$.

[50] J. Vargas Muñoz, M. A. Gonçalves, Z. Dias, and R. da S. Torres, "Hierarchical clustering-based graphs for large scale Approximate Nearest Neighbor search," Pattern Recognit., vol. 96, p. 106970, 2019, doi: 10.1016/j.patcog.2019.106970.

[51] A. Sengupta, V. Varma, M. S. Kiran, A. Johari, and R. Marimuthu, "Cost-effective autonomous garbage collecting robot system using Iot and sensor fusion," International Journal of Engineering and Advanced Technology, vol. 9, no. 1, pp. 1-7, 2019, doi: 10.35940/ijitee.a3880.119119.

[52] M. Muja and D. G. Lowe, "Scalable Nearest Neighbor algorithms for high dimensional Data," IEEE Trans. Pattern Anal. Mach. Intell., vol. 36, no. 11, pp. 2227-2240, 2014, doi: 10.1109/TPAMI.2014.2321376.

[53] L. Ai, J. Yu, Z. Wu, Y. He, and T. Guan, "Optimized residual vector quantization for efficient approximate nearest neighbor search," Multimed. Syst., vol. 23, no. 2, pp. 169-181, 2017, doi: 10.1007/s00530-015-0470-9.

[54] B. Fan, Q. Kong, B. Zhang, H. Liu, C. Pan, and J. Lu, "Efficient nearest neighbor search in high dimensional hamming space," Pattern Recognit., vol. 99, p. $107082, \quad 2020, \quad$ doi: 10.1016/j.patcog.2019.107082.

[55] X. Bai, C. Yan, H. Yang, L. Bai, J. Zhou, and E. R. Hancock, "Adaptive hash retrieval with kernel based similarity," Pattern Recognit., vol. 75, pp. 136-148, 2018, doi: 10.1016/j.patcog.2017.03.020 